\title{
Application of polyglycolic acid sheets for delayed perforation after endoscopic submucosal dissection of early gastric cancer
}

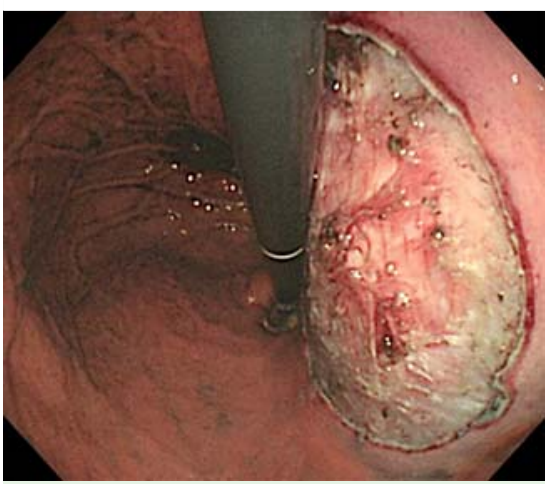

Fig. 1 A 62-year-old man with early gastric cancer located in the posterior wall of the upper stomach was treated by endoscopic submucosal dissection (ESD). The figure shows the ulcer floor immediately after ESD, with no signs of perforation. Pathological findings were 0 -llc, T1a (M), $20 \mathrm{~mm}$, ulcer scar (+), no lymphatic vessel invasion, surgical margin negative.

Since being developed and established in Japan, endoscopic submucosal dissection (ESD) has been widely used as a standard treatment for early gastric cancer [1]. Delayed perforation is an occasional complication of ESD, and despite its low incidence, it is a serious complication frequently requiring emergency operation [2-4]. Polyglycolic acid (PGA) sheets (Neoveil; Gunze Co., Japan), composed of bioabsorbable material, can be used to strengthen the ulcer floor after ESD [5]. We report the successful use of PGA
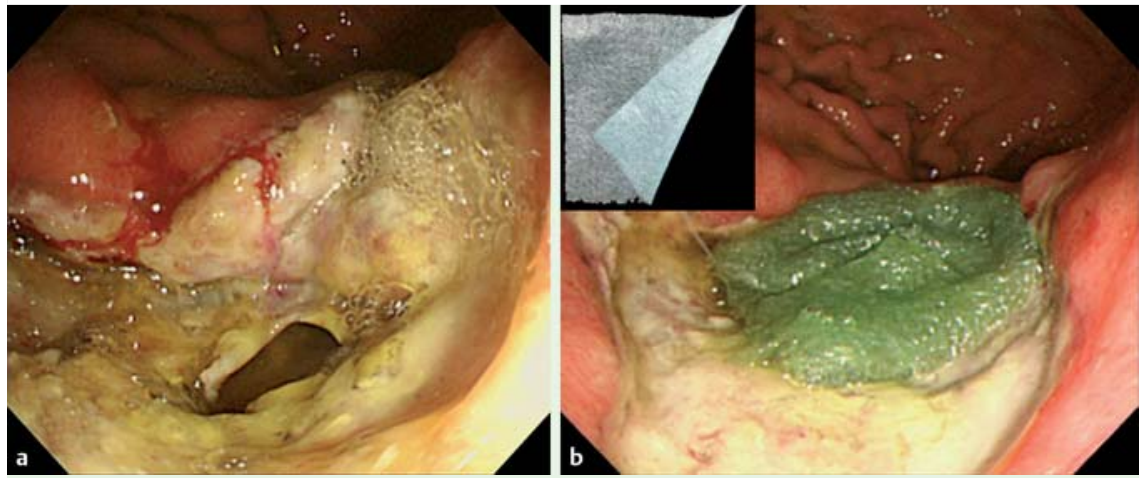

Fig. 2 Covering procedure using polyglycolic acid (PGA) strips. a On postoperative day (POD) 2 , esophagogastroduodenoscopy (EGD) revealed a perforation in the ulcer floor, which appeared thin and fragile because of inflammation. $\mathbf{b}$ To treat the perforation, a $100 \times 50-\mathrm{mm}$ polyglycolic acid (PGA) sheet (inset, upper left) was cut into small strips of approximately $20 \times 7 \mathrm{~mm}$. Fibrin glue was applied to the PGA strips, and the strips were placed over the perforation site using grasping forceps, followed by the use of endoclips to immobilize the PGA sheets on the mucosa surrounding the ulcer.

sheets as a conservative treatment for delayed perforation.

A 62-year-old man had early gastric cancer located in the posterior wall of the upper stomach. ESD was completed in 31 minutes with no complications or perforations ( $\bullet$ Fig. 1 ).

On postoperative day (POD) 1 , the patient was allowed to resume water intake. However, on POD 2, because of a fever as high as $39^{\circ} \mathrm{C}$ and a complaint of persistent epigastric pain, abdominal radiography was performed and revealed free air beneath the diaphragm. Esophagogastroduodenoscopy (EGD) on the same day re- vealed a 7-mm perforation and thin ulcer floor ( Fig. 2a) with unsuccessful endoclip closure, resulting in a tear in the ulcer floor owing to the fragile nature of the tissue after 2 days of inflammation.

We therefore cut a PGA sheet ( $\mathbf{F i g . 2 b}$ ) into strips and placed them on the site of perforation ( $\bullet$ Fig.2b). After shielding with PGA sheets, complaints subsided on POD 3. Complete coverage of the perforation site with PGA sheets was confirmed by EGD on POD 7 ( $\bullet$ Fig. 3 a), and the sheets had peeled off spontaneously by POD 13, revealing a completely healed perforation site ( Fig.3b). Scarring of
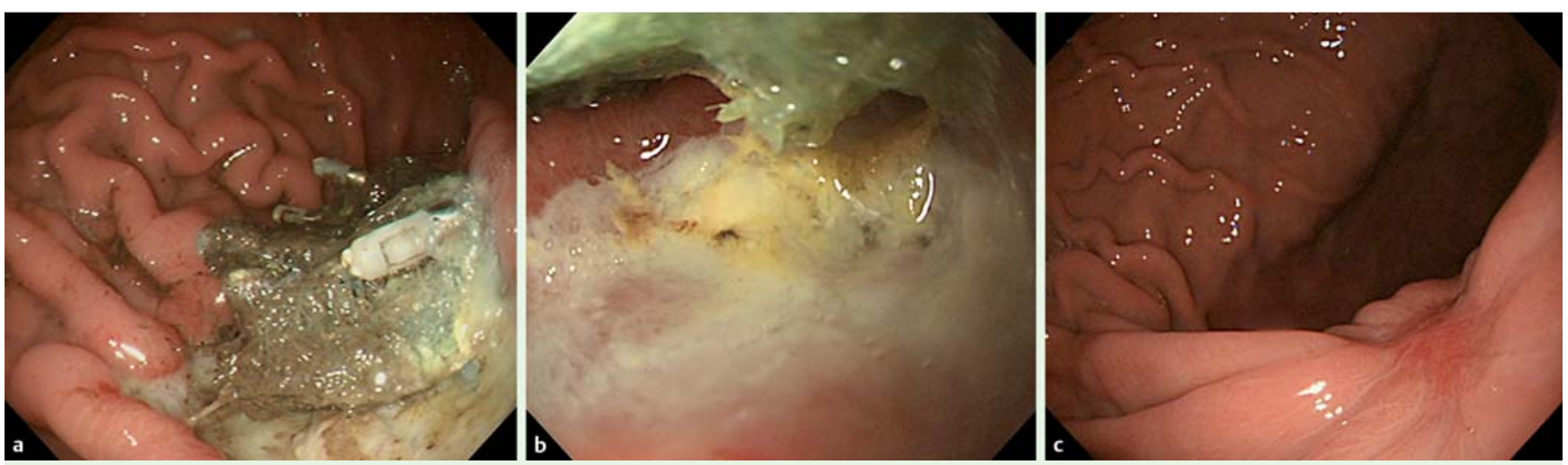

Fig. 3 Healing process of the delayed perforation. a Endoscopic view on postoperative day (POD) 7 showing the perforation site covered by polyglycolic acid (PGA) sheets. b Endoscopic view of the endoscopic submucosal dissection (ESD) site on POD 13 showing complete closure of the perforation site. $\mathbf{c}$ Endoscopic view after 2 months showing scarring of the perforation site. 
the perforation site was observed after 2 months ( Fig. 3c). Video 1 shows the PGA strips being placed on the site of perforation on postoperative day (POD) 2 followed by endoscopic views of the perforation site on POD 7, POD 13, and 2 months later.

Endoscopists may benefit from using the PGA shielding/coating method when it is difficult to close a perforation using clips.

\section{Video 1}

Placing the polyglycolic acid (PGA) strips on the site of perforation on postoperative day (POD) 2 followed by endoscopic views of the perforation site on POD 7, POD 13, and 2 months later.

Endoscopy_UCTN_Code_CPL_1AJ_2AD

\section{Competing interests: None}

\section{Hiroyuki Ono, Kohei Takizawa, Naomi Kakushima, Masaki Tanaka, Noboru Kawata}

Endoscopy Division, Shizuoka Cancer

Center, Shizuoka, Japan

\section{References}

1 Ono H, Kondo H, Gotoda T et al. Endoscopic mucosal resection for treatment of early gastric cancer. Gut 2001; 48: 225-229

2 Hanaoka $N$, Uedo $N$, Ishihara $R$ et al. Clinical features and outcomes of delayed perforation after endoscopic submucosal dissection for early gastric cancer. Endoscopy 2010; 42: $1112-1115$

3 Ikezawa $K$, Michida T, Iwahashi $K$ et al. Delayed perforation occurring after endoscopic submucosal dissection for early gastric cancer. Gastric Cancer 2012; 15: 111 114

4 Sekiguchi M, Suzuki H, Oda I et al. Dehiscence following successful endoscopic closure of gastric perforation during endoscopic submucosal dissection. World J Gastroenterol 2012; 18: 4224-4227

5 Takimoto K, Toyonaga T, Matsuyama K. Endoscopic tissue shielding to prevent delayed perforation associated with endoscopic submucosal dissection for duodenal neoplasms. Endoscopy 2012; 44: E414-E415
Bibliography

Dol http://dx.doi.org/ 10.1055/s-0034-1390730 Endoscopy 2015; 47: E18-E19

(C) Georg Thieme Verlag KG Stuttgart · New York ISSN 0013-726X

Corresponding author Hiroyuki Ono, MD, PhD Shimonagakubo 1007 Nagaizumi-cho Sunto-gun Shizuoka prefecture Japan

Fax: +81-55-9895692

h.ono@scchr.jp 